\title{
SRC Holdings: Winning The Game While Sharing The Prize
}

Vera L. Street, Salisbury University, USA

Marc D. Street, Salisbury University, USA

Christy H. Weer, Salisbury University, USA

Frank Shipper, Salisbury University, USA

\begin{abstract}
SRC Holdings Corporation, formerly Springfield Remanufacturing Corp., is a well-known manufacturing enterprise comprised of numerous companies spread across 12 Business Units engaged in activities ranging from manufacturing to packaging to management consulting and training. However, their primary business expertise and core competency is remanufacturing -the process of taking used transportation parts, for example, and returning them to their OEM (original equipment manufacturer) specifications. Headquartered in Springfield, Missouri, the SRC story is one of tremendous financial success, virtually from the beginning of the organization in 1983. At that time, a share of stock was worth 104; as of 2012, a single share is valued at about $\$ 361$ ! But although the company is well-known for its financial record, it is safe to say that it is most famous for its founder and current CEO, Jack Stack, and his insistence on converting his company into an employee-owned firm very early on. The subsequent success of SRC and the role its employee stock ownership plan (ESOP) played in this success is legendary. Thus, it's not surprising that both the SRC ESOP and Jack Stack play central roles in this case study.
\end{abstract}

Keywords: Employee Ownership; ESOP; Profit Sharing; Shared Leadership

\section{INTRODUCTION}

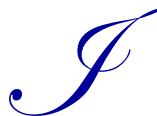

n 1981 Jack Stack, SRC's current CEO, was sent to Springfield, Missouri by his employer, International Harvester $(\mathrm{IH})$, to see if there was any hope of saving the small remanufacturing plant located there. Increased global competition, particularly from Japan, and the poor performance of the U.S. economy had wreaked havoc on many US manufacturing firms across a wide range of industries. IH had been particularly hard-hit, laying off thousands of employees and closing plants all over the United States. As Stack recalls "We [IH] closed 17 factories in a two-year period of time. We laid off 1000 people a week for two years...we went from 115,000 people down to 11,000 people in 1981-82."

In short order, Stack was instructed to sell the Springfield plant. But here the story takes a fateful turn: rather than scuttle the plant and layoff the employees, Stack and 12 other of his fellow managerial colleagues decided that they would buy the plant from IH and, along with their employees, run the business themselves. This was no easy task, however. The group did not have a lot of cash to put down towards the purchase and, consequently, had a difficult time procuring financing. Finally, after two years of offers, counteroffers, and loan rejections, they successfully secured financing and purchased the plant from IH for $\$ 9$ million in 1983. But the new firm, Springfield Remanufacturing Corp. (SRC), was born via precarious financial arrangements: Stack's purchasing group put up only $\$ 100,000$ of the $\$ 9$ million, and borrowed the other $\$ 8.9$ million at an $18 \%$ interest rate! Nevertheless, they were optimistic that they could make the firm successful. The following year they instituted an Employee Stock Ownership Plan (ESOP) and turned SRC into an employee-owned organization. And with that important move, the firm was about to achieve remarkable success that continues to this very day. Consider that in 1983 the stock of SRC was worth $\$ .10 /$ share but by 2001 it was valued at more than $\$ 81 /$ share. Revenues had grown from $\$ 16$ million in 1983 to $\$ 160$ million during this time and the number of employees had increased dramatically, from about 120 in 1983 to 900 in 2001. And SRC has continued the successful run over the past decade. Currently it 
has over 1200 employees, generates over $\$ 450$ million in annual revenues, and as of 2012, its stock was valued at $\$ 361$ per share.

The remarkable growth of the firm since 1983 has, not surprisingly, led to changes in its areas of business activity as well as to its corporate structure. Currently, the parent company is SRC Holdings, an umbrella entity that consists of numerous companies spread across 12 Business units engaged in activities ranging from manufacturing to packaging to management consulting and training. But despite this diversity of business interests, their primary business expertise and core competency is remanufacturing. In the case of SRC, remanufacturing is the process of taking used transportation parts and returning them to their OEM (original equipment manufacturer) specifications. Typically this involves dissembling, cleaning, machining, repairing/replacing, and reassembling the unit, the result being a product that is as good as or better than the original and is warranted as such. Their remanufacturing-focused divisions serve a wide range of businesses including those in the agriculture, automotive, defense, construction, mining, commercial trucking, and locomotive industries. And their clients are among the largest manufacturing firms in the world: General Motors, Komatsu, Navistar, John Deere, and CNH Global to name a few (Springfield ReManufacturing Corp., 2012).

SRC also has interests outside remanufacturing. For example, NewStream Enterprises (NSE) was created in 1990 to help clients in the transportation industries manage their supply chain functions more effectively and efficiently. NSE engages in a wide variety of activities including warehousing, inventory control, and facility management. And the success of NSE has allowed it to recently expand its functions to include government packaging and kitting (NewStream Enterprises, 2012). Another SRC subsidiary, SRC Logistics, specializes in thirdparty logistics to manufacturers, distributors, and retailers in a wide range of industries. SRC Logistics uses its location in southwestern Missouri as a strategic advantage that it can provide its clients in terms of shipping and warehousing activities (SRC Logistics, 2012).

Perhaps the most interesting - and definitely the most unique - unit of SRC Holdings is the Great Game of Business (GGOB) division. This unit takes its name from the best-selling business book Jack Stack published in 1992 as a response to the tremendous amount of interest in SRC that accompanied its meteoric rise from near oblivion just nine years earlier. In this text, and in his 2002 follow-up book, A Stake in the Outcome, Stack describes the elements and ideas comprising the GGOB philosophy and shows how they contribute to SRC's success. Importantly, Stack argues that these ideas can be adopted and successfully implemented by other firms across a wide range of industries as well. Indeed, it was this belief, buoyed by the success of both the firm and the books that led to the creation of the Great Game of Business division. Thus, from a broad perspective, the purpose of the GGOB division is two-fold: first, to promote and monitor the GGOB philosophy within and across the various SRC business units, and second, to make the GGOB philosophy available to the general business public via its managerial coaching, training, and consulting activities, publications, and products.

\section{CULTURE AND EMPLOYEE-OWNERS}

SRC takes great care to hire the right people to fit with their unique culture. The 1200 employee-owners are very experienced and, for the most part, reasonably well educated with the majority holding a high school diploma or more advanced degrees. SRC employees have been characterized as warm and open, of high quality, and having a lot of common sense. In general, employees are engaged, and they feel like they make a difference (and judging by SRC's tremendous success, they do make a difference! As Keith Boatright, Director of Human Resources stated, "This company is set up for a monstrously prosperous run." They don't want to just come in, put in their time, and go home. Boatright, for example, reflecting on the cultural effects at a personal level, says "I will be better for having been a part of this company in probably five years than at other companies. And I can't say [that] about many companies. Even though you might be productive and do good things, you will not necessarily be a better person." He continues on to describe how the work-life balance at SRC will most likely allow him to be healthier, better trained, and have the time and opportunity to engage in volunteer work in the community.

The combination of quality employees and the organizational and ownership structure of the firm help to create a culture at SRC that is an advantage in and of itself. As Boatright puts it "There is definitely a cultural advantage as much as there's a competitive advantage with SRC." At the core of this cultural advantage is the idea 
that having a great company is not just about building a good product or service, it's about building the company itself. When Jack Stack and his colleagues bought SRC from International Harvester, they decided that in order to put the focus on building a company, they would need a departure from the normal business model. Why? Because they wanted to build a business of business people. This cultural shift -- from a company of employees who just show up and make a product to a company of employees that are trained to become business people -- did not happen overnight. As Stack notes, ". . . it's a result of a pattern that we get the behavioral change that converts somebody into a business person and into a leader..." The basis of these patterns is an "open book" environment that strongly emphasizes sharing, explaining, and educating employees, particularly in the area of financial literacy. The goal is to encourage employees to own and understand the "numbers" driving their respective business units as well as the various SRC businesses as a whole. Consequently, this open book environment helps to bring the employees into the cultural fold, so to speak.

Because of these patterns and the fact that the employees have equity in the company, there is a strong ownership mentality among the employees at SRC. They tend to be driven and exhibit a strong desire to succeed. One may fear that such a mentality might lead to people stepping all over one another in order to get ahead. In fact, just the opposite is true. The employee-owners realize it is in their own best interest to work as a team to get the best outcomes for everyone. In effect, the incentives deriving from ownership are powerful forces for coordinating employee efforts. And when one considers the large financial benefits SRC employee-owners have enjoyed over the last couple of decades, it's not surprising to learn that most of its employees are committed to working there for the long haul. And in an era of low organizational dedication and high employee mobility, SRC's culture of long-term employee commitment is all the more impressive.

Many characteristics of SRC lead to the potential for long-tenured employees, but there are three that particularly stick out. First, SRC is strongly committed to protecting and helping its employees, particularly in difficult economic times. Second, employees have both the opportunity and the encouragement to explore career moves across the company, even to the point of changing job disciplines if they so desire. And third, SRC places a strong emphasis on succession planning.

Employees are the priority in the organization and job stability is a main goal of SRC. A critical reason for its success in this area is the firm's philosophy of protecting and supporting its employees. In tough times, rather than responding to reduced work demand and laying people off as a result, the company's focus on long-term growth helps to justify keeping everyone employed. For example, when recession hit in 2008 , the company chose to reduce working hours rather than lay off employees, so they could keep everyone employed. There is even a hierarchy of actions SRC is willing to provide employees, that are designed to provide buffer and reduce the likelihood of layoffs. In addition to these stabilizing, "work community" facilitating approaches, SRC also encourages employees to recommend qualified family members for employment. At SRC, there is no nepotism policy, so not only can you stay, you can even bring in your family to work for SRC if there are appropriate positions. (Jack Stack has two sons that work for SRC.) Indeed, Jack Stack says he and others want to make the world better and pass a better life on to future generations. In short, SRC really works to keep its employeeownership community intact and committed to staying with the firm.

A second important factor in SRC's efforts to develop and retain long-tenured employees involves the organizations' emphasis on employee exploration and movement within the company. Younger employees often don't know exactly what they do for a career and, for other more experienced employees, a change of pace in terms of functions and responsibility can be beneficial. SRC recognizes and actively addresses this. If, for example, an employee is willing to put in the effort and learn new skills, the company will help them out. Allowing employees to move to different functions can help them better understand the business as a whole, which is especially critical in a company like SRC where they strive to turn their workers into business partners. Consider, for instance, that SRC has employees that have moved to and from accounting, logistics, operations, and even marketing. There are also opportunities for international travel, tapping into SRCs business activities in Europe, China, and India. As Dennis Sheppard, General Counsel and CFO, put it, "I would say you're limited only by your own creativity and your own desire and willingness to work for what you want. You also have opportunities that - at least in this community you wouldn't find many places." This is not to say that employees are pressured to change jobs or to travel. Employees are respected regardless of their career choices. 
SRC also has a good understanding of the importance and value of institutionalizing succession planning as a component of their personnel philosophy. Such plans are highly supported throughout the organization and signal to employees - particularly those higher up in the corporate structure - that SRC values commitment and productivity and is willing to provide a long-term career mechanism that benefits both the employee and the firm. Promoting from within is an excellent way of signaling commitment to employees. And since the employees own the firm, all benefit from a well-executed succession plan, not just management and the employee in question.

Shifting gears a bit, an important question to consider is: Does the fact that SRC has an ESOP positively affect the company's culture? In the case of SRC, the answer is mostly "Yes," but this is not to say that everyone buys into the ESOP concept. It is important to keep in mind that the presence of an ESOP alone is not sufficient to guarantee a cohesive corporate culture nor is it sufficient to assure corporate success. As noted earlier, at SRC the employees aren't just owners, they are owners who think like business partners. They understand what being an owner means and how and why the company is performing as it is. And perhaps most importantly, they understand how to affect that performance. This is the direct result of their open book philosophy that requires financial literacy of the employees - that is, the employees "own the numbers" aspect. This is not to say that every single employee "gets it" or buys-in to the same level. Indeed, the business literacy that is required does not come easy for everyone. It can be very intimidating to someone who has not gone to college or not taken business courses. Indeed, those that don't "get it" likely won't get far in the organization. As Boatright describes:

Again, if you're punching the clock - and I worked in those kinds of environments where people they just want to come in, do their job and walk out. You are expected to do more here. So it's not a, hey I don't wanna do it. No, you've got to understand it. If you're gonna think and act like an owner, you've gotta understand the financials. And some people, that's just not there. And so yeah, I think some of our associates, they ride 'em and they ride each other. They are hard on each other. So if you've got somebody that's not stepping up, you've got a temp that's not fitting in culturally, yeah, they'll make it known and they won't go any further.

Though SRC has had tremendous success with its ESOP, there are potential cultural pitfalls it tries to guard against. One is that it can be easy for the ESOP to be viewed by the employees as an entitlement. This is particularly a threat at SRC because of its success in the marketplace and the resulting very comfortable financial environment for its employees. Although an entitlement attitude is something to be ever vigilant about, such an attitude is not currently a problem at SRC. One big aid for avoiding an entitlement attitude is accountability. Employees at SRC are clearly held accountable for the line item(s) to which they contribute and are expected to accept that responsibility. They also realize that an error by one employee can negatively impact many fellow employees.

Another potential threat specific to SRC's culture is the possibility of a substantial increase in turnover (from retirements) in the top ranks of the firm in the not too distant future. Most companies worry considerably about the effects of a new CEO, for example. In terms of the culture at SRC, this is particularly true given the dominant influence of Jack Stack. But SRC has two important characteristics that hopefully help to mitigate this risk. First, as previously mentioned, SRC has strong succession plans in place. This means that at least some of these potentially top-level vacant positions will be filled with insiders that already know, understand, and buy-in to the SRC culture. Even when it comes to outside hires, SRC has recently been very successful at bringing people into the fold - of course trying to take care that there is a cultural fit before they are brought on. And, in the case of Mr. Stack, it is likely that even if he does step down from his position as CEO, he will continue to have involvement with the organization (unless it seems he is stepping on the new CEO's toes.)

Despite the potential pitfalls, SRC's culture appears to be resilient - even through tough times. Unless there is a breach of trust between upper management and the other employee-owners, the culture is likely to remain a cornerstone of competitive advantage for SRC into the foreseeable future.

\section{SHARED LEADERSHIP}

Jack Stack once lamented, "Well, I came to the conclusion that in the years that I had been in business, I never, ever read a guru that said, 'Maybe people don't like working for somebody else." But rather than fight this seldom acknowledged fact, Stack decided to turn it to SRC's advantage. The result? SRC's extensive, proactive 
implementation of "shared leadership." At SRC, it really is the case that employees are not just employees; they're actually employee-owners. And this distinction is very important since the shared leadership philosophy empowers employee-owners with decision making discretion and authority. Consequently, employees are responsible for completing their daily activities and, in the course of so doing, empowered to make many decisions for themselves. Of course, productivity would suffer if employees were completely unaccountable for their behaviors and actions; SRC realizes this and addresses it through policies and procedures. Finding and maintaining the right balance between empowerment and formal policy is not always easy, but SRC expends great effort to maintain the appropriate balance.

The challenge of shared leadership involves continually building leaders throughout the organization. And although not all employees want the pressure or have the commitment requisite for leadership, at SRC an unexpectedly large number do. Indeed, as Stack notes, about three quarters of employees embrace the chance to be leaders. Not surprisingly, then, decision making authority and leadership permeate all levels of the organization. As Rich Armstrong, President of the Great Game of Business, puts it, it is critical that upper management earnestly believes that "... that the people in the organization can actually contribute to the success and it's not just the top guys that make all the strategic decisions and that's all that matters."

But shared leadership at SRC isn't based solely on a decentralized decision-making philosophy. Trust and accountability are two additional values that contribute to SRC's widespread shared leadership foundation. In order for employees to bring their thoughts and ideas into the open, they have to believe that upper management will respect them, appreciate them and, when deemed advantageous, act on them. SRC's management absolutely understands this and responds by turning employee belief into organizational reality. Not surprisingly, this two-way communication of trust can lead to great outcomes for SRC. Consider that some of the best ideas for changing SRC's remanufacturing processes have come from those who do the remanufacturing. In fact, ideas come from all parts of the organization. Jack Stack likes to recount the story of how a janitor at SRC gave him critical financial advice, which he willingly listened too (only later finding out that the man was a former stock broker), and the company ended up benefiting from this exchange.

On the other hand, employees recognize that shared leadership means that they will be held responsible and accountable for their actions and decisions. For instance, employees who grind crank shafts at SRC don't just have the important technical skills to do the job - they also know how their actions affect other elements of the organization. And perhaps most importantly, as employee-owners, they understand how it affects the bottom-line and why it is in their own best interest to take charge and be accountable for better outcomes. Because of this, there's not a lot of finger-pointing at SRC if something does go wrong.

Another important way SRC promotes shared leadership throughout the organization includes the use of committees, giving employees the opportunity to take leadership roles. For example, each of SRC's business units has an Ownership Culture Committee. This committee largely consists of a group of employees tasked with helping to spread an attitude of ownership throughout their unit, particularly among their new employees. A second example is the ESOP Steering Committee, another entity comprised entirely of employees. This committee is designed to help facilitate a widespread understanding and acceptance of the ESOP among employees. If past performance is any indicator, it appears that this committee has been very effective.

In one sense, a culture of shared leadership is not surprising in a company such as SRC. As we described briefly above, much of the leadership mindset is due to the nature of the internal environment at SRC. Essentially, SRC's employees are also owners who think like business people, understand their financial impact on the company, and are empowered to do something about it. In return for the substantial degree of responsibility that accompanies this shared leadership, employees are given the opportunity, support, and encouragement to "rise to the top and bring their ideas to the top." And, of course, there are also the financial benefits of being a part owner of SRC.

\section{HUMAN RESOURCES}

In many organizations, the human resource function plays little or no role in the strategic plans of the firm, instead often laboring under second-class status. At SRC, this is emphatically not the case. Thus, in this section, we look at the important role of HR at SRC from the perspective of the various HR functions. 


\section{Job Analysis Functions}

As is the case with most large companies, the HR department at SRC is responsible for the creation and monitoring of the numerous job descriptions. In a firm like SRC that provides employees input and leeway in their job behaviors, this is a considerable challenge for HR personnel. Although clearly not practical from a policy standpoint, Boatright says that Jack Stack would prefer that all job descriptions say "business person." This is understandable given that SRC explicitly treats employees as individual business persons. The need for strong HR job description-related actions has increased in recent years. Indeed, delineating responsibilities and skills has become more of a focus given SRC's extensive succession planning.

An important area of HR focus in SRC involves policies concerned with employee conduct in the organization. As Boatright indicates, incidents involving harassment, discrimination, and conflicts of interest are rare at SRC. This may well be due to the HR department's efforts at detailing and communicating expected employee conduct. SRC has a Code of Conduct as well as an employee handbook that, among other things, contains the firm's ethics policy. SRC also conducts harassment training.

\section{Recruiting}

Currently, SRC uses web services like Career Builder and Monster for recruiting. SRC also taps into talent from nearby universities through the use of careers fairs. In fact, the organization wants to become more involved in this area, particularly via building relationships with institutions that have specific programs geared toward its needs. However, much of the recruiting is by word of mouth. Since the employees tend to be strong proponents of the firm, current SRC employees represent an excellent recruiting tool. In a similar vein, family members of employees are commonly recruited as well.

One area that can be troublesome for SRC when recruiting new employees is that they do not pay top wages. This liability is strongly offset by the tremendous success of the ESOP: prospective employees can reasonably believe that if they make a career for themselves at SRC, they can have substantial financial assets when they cash out their ESOP shares. It should also be noted that SRC has a strong benefits package and, according to many employees, there are important intangibles (such as career stability) that go along with working at SRC. Also of relevance is the fact that Springfield, Missouri has a low cost of living.

\section{Selection}

The selection process varies throughout the organization, but it is fair to say that it is an extensive process. Many of the current employees at SRC are empowered to make decisions regarding new hires. And because of the strong ownership mentality that permeates the firm, these employees are motivated to identify those prospects most likely to succeed at SRC. The following quotes from Keith Boatright and Ron Guinn embody this idea:

"It's an investment and at the end of the day, one, you need to make darn sure that you need the position and two, whoever you get, you basically write 'em a check, giving them your equity. So, if you're gonna go and do that, you better make darn sure that that investment is understood by everybody."

"And there's a subliminal thing that happens there because once you get in the door, your panel of peers to get you in here, feel some level of responsibility because they brought you here and they told the rest of their partners that this is the person that we want so. I've definitely have seen people that served on panels' kind of take someone under their wing and make sure they get started well. They got a vested interest in seeing that person succeed."

An additional method that SRC sometimes employs is through the use of temporary positions and internships as a sort or proving ground, before individuals are hired permanently. This allows both the firm and the prospective employee a chance to try each other out, so to speak. 


\section{Training}

Rich Armstrong describes the importance of training to SRC by noting that SRC has "doubled-down" on training. Indeed, the organization engages in many different types and modes of training, working diligently towards achieving the right mix of training and identifying the most efficient schedule for the various trainings programs. Examples of types of training at SRC include: financial literacy training, technical training, and entrepreneurship training. Among the different forms these training may take are classroom training, simulations, experiential activities, and informal training.

One of the most important aspects of training at SRC is training for the Great Game of Business. This area of training helps SRC's employee-owners to think and act like business people. By becoming financially literate and developing a deeper understanding of how SRC conducts its business activities, employees are capable of much more than merely focusing on the basic task requirements of their job. Because they are able to see the big picture, they are in position to make contributions that can better the organization. Such contributions frequently have the potential to positively affect both the employee's and the firm's bottom line. For instance, they may suggest a process improvement that will save money or they may foresee and help the company avoid a potential safety issue. Training the employee-owners at SRC to be business people rather than just task masters really provides SRC with a competitive advantage and sets it apart from its competition.

At SRC, employees are also trained on the specifics of their employee stock ownership plan. Employees are typically given information about the ESOP via their employee handbook when they are first hired. Their ESOP knowledge increases over time as they come to experience the ownership culture, and when they are closer to being able to see the financial rewards of the ESOP.

Cross-training is another important aspect of SRC's training approach. Cross-training employees can serve to not only allow employees to broaden their horizons and keep them interested, but also can serve to help protect jobs in difficult times. That is, if a cross-trained employee is currently working in an area that is seeing a downturn (and having consequent overstaffing), the employee could be transferred to another area in which they are needed more, rather than being laid off.

In addition to these formal training mechanisms, a great deal of informal, hands-on training happens at SRC. Often an informal mentor of sorts will help instruct the employees on the proper way to do the tasks and processes required by their job. These employees are paired together until the trainee can perform the job on his/her own, which frequently requires some form of certification. This type of informal training can involve a new employee or an existing employee who is learning a new skill. Also, it's not uncommon for an experienced employee to try to help a new employee settle in and get up to speed, especially if the experienced employee was involved in the hiring decision of that employee in the first place. Many SRC employees feel a responsibility not just to the new employee whom they advocated, but also to other existing employees. This is so because their support of the new employee says, in effect, that they view the new employee as a potentially good partner, one whom with they're comfortable sharing the equity in the firm.

Also of note, SRC also offers tuition reimbursement. This is offered for technical and managerial development. Local institutions offer not only degrees, but also certificates in areas ranging from particular engineering expertise, to purchasing, to managerial disciplines. And along these lines, SRC has a partnership for a specialized technical program with a local college. Various divisions of SRC have also been considering a formal mentor program, and a leadership program is another training idea that may materialize in the future.

Many benefits can be seen from the training that goes on at SRC, and as such it is viewed as a valuable investment rather than a required expense. Training is viewed as part of the growth engine at SRC. As Jack Stack puts it, "And so what we began to see is the more we taught, the more people taught us." Well-trained employees are needed in place to facilitate growth within a current SRC business and they are needed to manage the spinoff/creation of new business. The employees are also winners since they gain skills, advance in the organization, and generally make themselves more valuable. 


\section{Evaluation and Retention}

Currently, SRC is experimenting with a performance evaluation system that allows attractive opportunities for personal growth. This system involves the development of "profiles" that has the potential to really help employees understand where their interests lie. Traditional performance evaluations are also conducted at SRC and vary by division and position. Some are done by supervisor rating and some are done collaboratively. Interestingly, for most divisions, performance evaluations are not tied to base compensation. However, there is a lot of performance recognition done within the organization. For example luncheons, outings, and awards are used to highlight exceptional achievements. Importantly, SRC employees generally understand the business, and thus they know on their own when they are failing or succeeding and are typically motivated to act accordingly.

Such investments in finding the right people to work at SRC are consistent with SRC's commitment to protect and keep those employees once they are found. Another way to try to keep employees is through offering valued benefits. Some of the benefits include generous holidays, bereavement leave, wellness programs, tuition reimbursement, and retirement planning sessions. Training is also valued by employees. At SRC numerous training opportunities are available for employees to better themselves.

Thus, SRC has many HR activities aimed at successfully recruiting and retaining the very best employees. Of course, this does not mean that nobody ever leaves. Recent combined voluntary and involuntary turnover has run about $13 \%$ annually. From an involuntary side, SRC tries to hire the right people in the first place, but there are cases where employees just don't work out. Such terminations are primarily decided at the division level. The corporate level usually has little involvement other that of legal and procedural oversight. As far as voluntary turnover is concerned, it should be pointed out SRC has had a lot of retirements recently, particularly in their more mature businesses, and they hire quite a few current college students (in more entry level positions) that SRC knows eventually move on. However, they have to guard against their talent being hired away, given that they work for a well -respected company.

\section{OPERATIONS}

The introduction to this case study noted the wide variety of businesses and industries SRC is involved in, ranging from logistics support to employee and management business training. But its bread and butter, so to speak, involves the field of remanufacturing. The various companies within SRC Holdings remanufacture products such entire engines, fuel systems, and electric components for a wide variety of markets including agriculture, trucking, mining, and various construction-related fields. Remanufacturing is a very complex process, much more so than repairing or rebuilding. In remanufacturing the product is completely disassembled and cleaned; all parts are inspected, and if necessary, replaced. The endpoint of this process is to return the entity involved to its OEM specifications. SRC's expertise in the remanufacturing process is so high that the remanufactured product is as good as or, in many cases, better than new. Indeed, the warranty will meet or exceed that of a new product (Springfield ReManufacturing Corp., 2012).

Below are a few of the policies, in this instance from SRC Electrical, that are instrumental in driving SRC's remanufacturing activities and doing so with surprisingly efficient asset utilization:

- $\quad$ Closely monitoring and working with vendors (shipments are checked and vendors can go on probation if there are issues)

- Using ideas from lean techniques like the "5 S's" (Sort, Set in order, Shine, Standardize, and Sustain) (Environmental Protection Agency, Lean Thinking and Methods, 2012)

- $\quad$ Updating testing equipment

- $\quad$ Giving incentives for employees to cross-train and/or gain additional skills

As previously described SRC Holdings considers its employees to be a source of competitive advantage. Thus it is not surprising that, in terms of operations and productions, the organization places a high priority on employee safety. From updating equipment to using more people-friendly solvents for cleaning, SRC is constantly working to keep its employees safe. Employees watch out for both themselves and others where safety is concerned. 
Importantly, safety is not taken as a given - it is constantly monitored and reinforced. Recognizing achievements, as well as concerns, regarding safety are commonplace at meetings. In sum, then, SRC Holdings' operations can be characterized as quality, efficient, and safe.

\section{MARKETING AND SALES}

SRC's Marketing and Sales teams have two major roles. The first involves developing and maintaining strong relationships with the existing customer base. Many of SRC's products are sold to vehicle OEMs such as John Deere and CNH Global. Inasmuch as SRC strives to establish and build long-term relationships with these OEMs, they typically view and treat them as valued partners rather than just customers. A very important element in this area is that, unlike some of their competitors, SRC usually doesn't compete with the OEMs by selling to the aftermarket. Instead, they help the OEMs and their dealers to sell SRC's products, a policy that is very much appreciated by their partners.

Not surprisingly, much of the marketing done is by word-of-mouth, frequently via the relationship building with the OEMs. Building strong, solid relationships motivates the OEMs to portray SRCs as a credible supplier to end consumers. From SRC's perspective, confidence in the quality of its products, services, and customer service is the foundation on which these relationships are built, a confidence that ultimately carries through to the OEMs. Consider that, for example, that it is not uncommon for customers to come to the plants and talk to the people actually doing work on their products and work orders. Indeed, often times SRC's customers will cultivate relationships with specific SRC employees, to the point that they know they can call on them specifically if they have a question or concern about their orders.

The second major role marketing at SRC focuses on involves developing forecasts and communicating this information to everyone in the organization. The basis for these forecasts is their strong knowledge of both their existing client base and of those firms not yet customers. Twice a year the sales and marketing personnel compile and analyze information about their customers, potential customers, and competitors and present this information to everyone in the company so that firm-wide forecasts and projections can be made. These reports are relied upon heavily for workforce planning, product planning, and determining strategies on how to best rise above the competition. Clearly, the Marketing and Sales teams at SRC play a pivotal role in the firm's strategies and tactics.

\section{FINANCE AND FINACIAL SHARING}

As noted in the introduction to this case, SRC started out on a very precarious financial footing. But through the hard work of its employees and the insight of top management, SRC not only survived, but established a financial track record of envious proportions. Indeed, recently Jack Stack indicated he would not be surprised to see SRC's stock price more than double over the next couple of years.

Currently, SRC's revenues are approaching the $\$ 437$ million mark and it expects to generate earnings of about $\$ 24$ million in 2013. Furthermore, in order to save on interest costs, it intends to eliminate long-term debt (while maintaining a reasonable level of operating debt) in the next few years. Finally, its current ratio tends to be fairly high, and its capital intensity tends to be relatively low for its type of business, both positive signs. Thus, even in these currently troubled economic times, SRC is a financially sound organization.

In one sense, given that most employee-owners at SRC actually understand the financials and how their personal actions play a role in the financial health of the organization, it's not overly surprising that the firm is financially solid. Of course, it's also not surprising that these employee-owners want to share in the company's financial rewards. What may be a bit surprising, however, is that, for the most part, the basic compensation at SRC is neither explicitly tied to the financial health of the company nor to the employee's specific contribution to the bottom line (i.e., it is not based on employee performance evaluations).

There are however, several ways that the financial gains of the company are shared with employees, the most obvious being through the shared ownership in the employee stock ownership plan (ESOP). Consider that, for example, if an employee participated in the ESOP when it started in 1983 and continued through until this current 
year, they would have at least $\$ 400,000$ in the ESOP. And although SRC has had opportunities to sell the corporation outright to external buyers - thus making a lot of money for many SRC executives - the firm has remained loyal to its original employee-centered principles. In fact, SRC has recently moved from being partly owned by management to being $100 \%$ owned by employees via the ESOP. This was done for a number of reasons, with the main one being to pass the company on to the next generation. Currently, the plan is functioning such that each year after the company valuation, the employees receive shares proportional to their eligible compensation.

In addition to the ESOP, SRC provides several other financial benefits for its employees. Three of these are options, bonuses, and the $401 \mathrm{k}$ program. The option program, which is currently being redesigned, gives greater incentives for performance to some department managers as well as various executives. Bonuses are tied to specific goals across the various SRC units and serve to incentivize desired behaviors on the part of the employees. The $401 \mathrm{k}$ program involves a five percent match of employee contributions by the firm. Beyond simply monetary considerations, the $401 \mathrm{k}$ program is beneficial in two other ways: first, it gives the employees the ability to diversify their portfolio beyond their ESOP stock holdings; and secondly, the assets in the employee's $401 \mathrm{~K}$ can be used to help secure a loan if so desired. In sum, the strong financial position of SRC provides numerous financial benefits for the employees as well.

\section{INNOVATION}

In today's globally competitive environment, organizational growth through innovation and development is absolutely imperative. A commitment to innovation drives product enhancement, the creation of new product lines, and occasionally even the development of a SRC company. Innovative developments affecting internal processes can lower costs which, in turn, typically lead to more sales, higher revenues, more profit, and overall organizational growth.

None of this is lost on SRC where emphasizing innovation contributes mightily to its tremendous track record of growth. Jack Stack captures this sentiment when he states that SRC is trying to. "... train people to build innovation. Build creativity. Build entrepreneurs." Not surprisingly, a great deal of research, development, and experimentation takes place at SRC. SRC enjoys a large degree of success with its innovation efforts, frequently more so than its competitors. These efforts are typically successful because the employee-owners at SRC have a strong understanding of the business aspects of their innovative ideas. And since employees realize that they will be accountable for their ideas - and have to convince others as to their merits - the likelihood that good ideas come to the table is increased. In terms of innovation and growth, SRC is able to leverage the knowledge and incentives for success that drive their employee-owners.

By way of illustration, consider the following account involving irrigation systems. Employees at SRC worked out how to convert a diesel engine for an irrigation system into a natural gas engine, potentially a very important innovation. At most firms, a technical innovation such as this would be the end point of the employee contribution. Not so at SRC. Employees calculated that such an engine could provide up to $67 \%$ savings and pay for itself within six months. They also helped to come up with a marketing plan. They knew who to work with and how to go about making this specific innovation profitable. This brief account highlights an important benefit of employee-owners: they have both the knowledge and the incentives to propose, realize, and deliver innovative technical solutions as well as the financial and overall business savvy to understand the business implications of their ideas and solutions.

As a result of such fruitful innovation, growth has been a common occurrence at SRC and, despite the projected weakness of the overall US economy, is expected to continue into the near term as well. It should be noted, however, that growth frequently poses challenges for an organization. At SRC, two such challenges involve hiring new employees. Often, a large influx of employees can make integration into the organizational culture a substantial difficulty. Because SRC has such a strong and unique culture, it is not uncommon for new hires to struggle in truly understanding and buying into the overall corporate philosophy. A second concern involves finding enough people with the requisite qualifications and experience. Keith Boatright believes this is the biggest obstacle to growth at SRC. Consequently, SRC is trying to recognize that although they definitely want to foster innovation and expansion, it's probably wise if the firm's growth is carefully managed and controlled. 


\section{EXTERNAL ENVIRONMENT}

There are many forces in the external environment that play important roles in how SRC makes its business decisions and executes its various strategies. At the business environment level, these forces include key constituents such as customers, suppliers, and competitors. At the larger, more general environmental level, trends in the economic and political-legal aspects of our society can have significant impact on SRC's activities.

In terms of the business environment, an important factor involves those businesses with which SRC has established and maintained relationships. As noted previously, SRC typically has developed strong relationships with many of the OEMs to which it sells parts. Recall that whereas most other remanufactures and manufacturers fiercely compete with the OEMs by selling parts to retailers, SRC has generally chosen to not take this route. Developing and maintaining relationships with suppliers is also emphasized strongly at SRC. The increased degree of coordination that frequently results from these strong relationships is particularly valuable in addressing the challenges stemming from the global nature of SRC's supply chain.

An interesting strategy employed by SRC involves the development of joint ventures. SRC leverages its unique cultural and managerial expertise by establishing partnerships with companies often with the intent of selling its stake in the joint venture once the new entity is up and running. An important benefit to SRC from successful joint ventures is the resultant liquidity from the buyouts. And apparently SRC has become pretty efficient and successful with these efforts. As Rhonda Alexander, Great Game of Business Coach Development \& Trainer at SRC put it “. . nobody gets a joint venture from zero to sixty faster than SRC. .." And the sixty she is referring to is $\$ 60$ million.

The competitive element is also another important variable in SRC's business environment. Competitive pressures keep prices low and margins tight for most of the industries in which SRC operates. As such it is critical that SRC keeps a close watch on their competition, and more broadly, on the industries in which they operate. Consequently SRC expends much time and energy monitoring and collecting information on their competition. For example, they have scoreboards where they keep score of the strengths and weakness of their main competitors as they relate to those of SRC. They gather information from company websites, from customers, from banks that follow particular industries, and from the competition itself through relationships they have established over time.

The overall labor market currently poses substantial challenges to SRC as well. As mentioned earlier, because of its record of growth and its unique employee-ownership culture, it can be challenging for SRC to find the right talent to staff its various companies. Consider, also, that the United States currently has a relative shortage of engineering talent in the labor pool. For firms with heavy engineering needs like SRC, this poses a particular challenge. Jack Stack also points out that the decline in standing of science, technology, engineering, and math in the American educational system is particularly harmful to the business models and ideas championed by SRC. And as a final observation, consider that SRC's employees are often highly sought after by other firms, thus forcing SRC to be very vigilant with their employee retention efforts.

Moving from the business level to the general environment, as Stack sees it; one of the biggest external threats to SRC is the decreasing economic freedom in the United States. In particular, the increasing influence of government entities via business regulations is a serious challenge for SRC. SRC has traditionally been very successful at creating new businesses: amazingly, in less than 30 years, they created over 60 businesses. In the current climate, however, creating a new business has become increasingly difficult because there are more regulations and greater costs required to start the business in the first place. Existing SRC businesses feel the regulatory burden also -- the Environmental Protection Agency (EPA) and other governmental agencies have been increasingly tough on products like the engines that SRC remanufactures. Also, a benefit that SRC has enjoyed in the past was the flexibility from employees being able to fill in where needed across the different companies in SRC's portfolio. This too has become more difficult because of increased regulation. Current trends in regulation have not been favorable to the ESOP business structure as well. And the administrative costs associated with simply following and understanding new rules and regulations are considerable and are likely to keep growing in the future. 
Finally, the most recent economic downturn needs mention. SRC was fully expecting the economic downturn, and they felt they were mostly ready for it. SRC management is constantly examining possible business contingencies and developing potential plans for when tough times do occur. In fact, SRC intentionally developed their portfolio of businesses and products to include those that fare better in a fast growing economy and others that perform relatively better in a downturn. For example, early on the truck market was huge for SRC, but they soon realized that that particular market faces a recession every 6 years or so. They also realized that car parts went up during these recessions and acting on these two pieces of knowledge, diversified their business portfolio accordingly. All of this is not to say that SRC has been unscathed in the current economic slowdown. Various divisions at SRC have needed to invoke less than desirable measures such as temporary cuts in employee hours and/or pay. Nevertheless, SRC works hard to live up to its cultural values by making every effort to keep jobs first and foremost, even if that means other benefits have to be cut to do so. It's important to point out that such measures are perhaps better accepted at SRC than other firms since their employee-owners understand why the measures are necessary in the first place and how they affect the overall health of the organization.

\section{THE GREAT GAME OF BUSINESS}

SRC's Great Game of Business (GGOB) initiative incorporates many of the previously discussed business elements including employee financial literacy, shared leadership, employee equity ownership, and incentive-type pay plans. But it also emphasizes two additional elements that are critical to SRC's success: transparency and the spirit of competition. Although the GGOB is practiced across the numerous business units of SRC, its specific implementation varies from division to division. This flexibility allows each division to determine what works best for them. And, if a division tries something new or unique and is very successful, the knowledge of this new best practice is shared with other divisions.

A very important GGOB element involves tapping into the tremendous productive potential of competition. As the name "Great Game of Business" implies, business is viewed as a game in which SRC employees are competing in a variety of settings as a team against competitors. According to Jack Stack, there are three components to a game. First, there are rules that, in business, are set by the marketplace. Second, there is a scorecard. In the business environment, the scorecard consists typically of financial metrics. Generally speaking, the better the financials, the more successful the business. Third, there must be a prize for the winners - the "what's in it for me?" aspect that drives the individual employees. At SRC, this prize takes many forms including increased wages, better benefits, bonuses and ownership equity in an organization that is succeeding.

The use and emphasis on games is ingrained at SRC. Although the ultimate game is to win in the marketplace, games are conducted at many different levels and across a variety of timeframes. At the macro level, for example, games will be run at the corporate or division level and focus on a couple of key metrics for an entire year. This focus is called the Critical Number. On a smaller level, games may also involve a specific area of the production floor and focus on achieving a particular outcome across a time period as short as week or month. The point here is that games are used at all levels of the organization and can be very specifically targeted. And, as Stack notes below, they serve multiple purposes in the organization:

We use games to incent or reward or to teach? And to have people have fun in their organization. And every time they see that goal, they throw that fist up in the air and they feel good about what they did.

In order for the use of games to be successful, the employees that comprise the various teams must know what is going on. Consequently, transparency is another important cornerstone of the Great Game and is prevalent throughout the SRC companies. Indeed, in "Open-Book Management: Its Promise and Pitfalls," author Tim Davis says that Jack Stack at SRC implemented the first complete system of open-book management, a popular management technique with transparency as its core (Davis, 1997). Consider that daily cash statements are available to any employee, and everybody sees weekly financials. About every two weeks there are meetings between the corporate staff and general management to look at their strategies and identify any potential issues that may be surfacing. Additionally, there are company-wide monthly meetings where reports from not only the corporate staff, but from various committees are shared with employees. And, every six months, the sales and marketing teams make a presentation to everyone in the company. And information and education about the ESOP is consistently available to employees. 
It's important to point out here that a lot of the information made readily available to the employees does not come from the top to be disseminated downward. Actually, much of the financial information originates at the bottom, is consolidated at the top, and then is redistributed back out to the employees. Thus, financial numbers are tracked and conveyed upward from the department that is actually responsible for them in the first place. Jack Stack explains why this is so important:

And there's no ands, ifs, or buts and no grey areas when you're talking about numbers. And numbers are nothing more than stories about people. That's all numbers really are, all right? So if you can get people to own the numbers, you know, then you can begin the process of knowing where to make a difference.

A prime illustration of this transparency-driven, bottom-up ownership of the numbers at SRC involves something known as the "weekly huddle." At SRC Electrical, for example, the weekly huddle is intense, informative, competitive, and fun. Employees file into a room and sit in teams of 10 or so with their binders of relevant information. Some general announcements and discussion occurs regarding safety and quality issues. Then attention turns to the giant income statement template on the wall. Employees responsible for particular line items are called upon to report those numbers. When calculations are necessary, the teams plunge in to find the answer. As the income statement is generated, the leader of the huddle calls attention to any areas of concern or interest that need to be discussed. After the income statement is complete and discussion subsides, the huddle concludes with a game of "SRCopoly," a fun, though competitive, way of facilitating better understanding of their balance sheet. Witnessing a huddle in action definitely allows for an understanding of how and why employees at SRC so readily buy-in to the ideas and behaviors needed for the continued success of the organization.

It is important to point out here that consistency, repetition, and the development of predictable behavioral patterns are also important keys to the success of the Great Game of Business. These aspects allow employees to know what to expect when, help to reinforce accountability for everyone, and help employees to better understand the business side of issues via repetition and application of key concepts.

Underlying the effectiveness of GGOB elements such as the huddle is the training employees receive early in their employment. In the first few weeks at SRC an employee is typically trained on the more traditional aspects of their job, as might be expected. However, they also sit in on the huddles and, as a result, begin to develop an understanding that there is much more to their job than the standard expectations. At that point they start more formal training, beginning with the basics of financial literacy, the basics of the Great Game, and on to employee ownership and SRC's ESOP.

The corporate-wide advocacy of transparency, consistency, and employee education was present at the genesis of the Great Game of Business. Looking back, Jack Stack recalls:

And so I promised - I said very, very simply, "We will teach you everything that we learn." We told them that the objective is the company. That the responsibility will be to create a great company. We knew that they could create great products. We knew that they could create great services. We spent 115 years [Manufacturing in America] teaching people how to do their job. I would contend, it's probably the 1 percent we talk about all the time that really understand the metrics of the company, all right?

And so I promised them. I said "Look, we will, we will build programs. We will accelerate the learning process. We will get you to the point of getting it where you can interpret the metrics and then you can make the decisions based on the facts and figures that you have in front of you."

And this approach has worked. The GGOB has been so successful, that there is now a Great Game of Business division at SRC, as previously mentioned. Not only do they handle much of the formal internal training across the various SRC companies, but they also offer their expertise to other unrelated companies by teaching them how they would benefit from implementing the ideas and concepts comprising the GGOB. And there is plenty of external praise from the business media suggesting that it's doing a good job spreading the GGOB philosophy to the American business community at large. BusinessWeek, noting that representatives from more than 4000 companies across the globe have visited the GGOB unit in Springfield, called SRC a "Management Mecca." GGOB has 
recently been featured on MSNBC and in the New York Times and the Wall Street Journal. The Great Game of Business book was selected as one of the 100 Best Business Books of All-Time. In July of 2013, it was reissued as an expanded $20^{\text {th }}$ anniversary edition. It debuted as the \#1 best-selling business paperback according to the Neilson Book Scan. In addition, the GGOB philosophy was chosen as the Number 1 Most Innovative Business Practice by INC magazine (About the Great Game of Business, 2012).

\section{LOOKING FORWARD}

The worker-owners at SRC recognize that they face many challenges and obstacles about which they have spoken candidly. They believe that the GGOB philosophy that they practice every day throughout SRC Holdings will allow them to overcome whatever challenges and obstacles may come their way. Apparently, over 4000 companies and multiple media outlets at least partially agree with the worker-owners. The GGOB philosophy and it associated practices represent a departure from business as usual. Will the unusual become the usual?

\section{QUESTIONS FOR DISCUSSION}

1. Describe the culture at SRC.

2. Discuss the ways in which SRC exhibits open book management.

3. Discuss the unique Human Resource Practices that SRC employs.

4. Discuss the implications of being an ESOP for SRC and its employees.

5. What are some possible challenges that SRC may face in the coming decade?

\section{ACKNOWLEDGEMENTS}

Many sources were helpful in providing material for this case, most particularly the worker-owners at SRC Holdings who generously shared their time and viewpoints about the company to help ensure that the case accurately reflected the company's practices and culture. They provided many resources, including internal documents, data and stories of their personal experiences. This research was partially supported by the Foundation for Enterprise Development and the National Center for Employee Ownership under a Rosen Ownership Opportunities Fund (ROOF) Grant.

\section{AUTHOR INFORMATION}

Vera L. Street (Ph.D. Florida State University) is an Associate Professor of Management in the Franklin P. Perdue School of Business at Salisbury University. Her research interests include competitive dynamics and employee ownership. Her articles have appeared in the Journal of Management, Academy of Management Executive, Journal of Business Venturing, Journal of Business Ethics and others. Additionally, with Marc D. Street, she co-authored the 2nd and 3rd editions of Taking Sides: Clashing Views in Management. E-mail: vlstreet@ salisbury.edu

Marc D. Street (Ph.D. Florida State University) is an Associate Professor of Management in the Perdue School of Business at Salisbury University. Prior to entering academia, he held several jobs in the private sector, including four years as a financial consultant for the Baltimore office of Merrill Lynch. His primary area of teaching involves the social and moral business environment, while his research interests focus on business ethics and employee ownership. E-mail: mdstreet@salisbury.edu

Christy H. Weer (Ph.D. Drexel University) is an Associate Professor of Management and Associate Dean in the Franklin P. Perdue School of Business at Salisbury University. Her research interests include issues related to the work-family interface, career development, gender and diversity in organizations, and employee ownership. Her articles have appeared in the Journal of Vocational Behavior, Group and Organization Management, Journal of Applied Social Psychology, and others. E-mail: chweer@salisbury.edu

Frank Shipper (Ph.D. Utah) is Professor of Management in the Franklin P. Perdue School of Business at Salisbury University. His current teaching, consulting, and research interests are managerial/leadership skills development, and employee ownership and culture. His articles have appeared in the Academy of Management Journal, Organizational Dynamics, Leadership Quarterly, Human Relations, Academy of Management Learning \& 
Education, and others. He has been recognized by the Academy of Management and the Center for Creative Leadership for his work on management development. As a consultant, he assists organizations in developing and validating their management development processes. E-mail: fmshipper@salisbury.edu (Corresponding author)

\section{REFERENCES}

1. About the Great Game of Business. (2012). Retrieved July 9, 2012, from http://greatgame.com/about/

2. Davis, T.R.V. (1997). Open-book management: Its promises and pitfalls. Organizational Dynamics, 25(3), 7-20. doi: http://dx.doi.org/10.1016/S0090-2616(97)90044-9

3. Environmental Protection Agency, Lean Thinking and Methods. (2012). Retrieved August 6, 201 2, from www.epa.gov/lean/environment/methods/fives.htm

4. NewStream Enterprises. (2012). Retrieved August 2, 2012, from www.newstreaming.com/

5. Springfield ReManufacturing Corp. (2012). Retrieved August 2, 2012, from www.srcreman.com

6. SRC Logistics. (2012). Retrieved July 8, 2012, from www.srclogisticsinc.com/homepage.php 


\section{NOTES}

